American Journal of Applied Sciences 5 (11): 1437-1441, 2008

ISSN 1546-9239

(C) 2008 Science Publications

\title{
Synthesis of Mesoporous Titania with Surfactant and its Characterization
}

\author{
T. Benkacem and N. Agoudjil \\ Departement of Chemistry, Laboratory of Physico-Chemistry of Materials and Environment, \\ Uuniversity of Sciences and Technology Houari Boumediene, \\ Bp 32 El Alia Bab Ezzouar Algiers, Algerie
}

\begin{abstract}
A mesoporous titania was obtained by gelation from Ti-alkoxide in acidic solutions with addition of surfactant cetyltrimetylammonium bromide $\left(\mathrm{CH}_{3}\left(\mathrm{CH}_{2}\right)_{15} \mathrm{~N}\left(\mathrm{CH}_{3}\right)_{3} \mathrm{Br}\right)$ using a sol-gel process. The effects of surfactant concentration on synthesis of mesoporous titania were studied. The structural characterisation was studied by differential thermal analysis, infrared spectroscopy, X-ray diffraction. Studies by X-ray diffraction showed that crystallisation of $\mathrm{TiO}_{2}$ powder occurs at $200^{\circ} \mathrm{C}$, above $200^{\circ} \mathrm{C}$ we obtained a mixture of two forms-Anatase and rutile. The textural characterisation by nitrogen adsorption-desorption allowed us to observe the variation of the surface area, porous volume and pore diameters according to temperature and [CTAB]/[Ti-alkoxide] molar ratio. The analysis of the results shows that addition of surfactant residue increases considerably its pore diameters. The deposit thin layers has been realized with a sol prepared with the destabilization of colloidal solutions process. Scanning electron-spectroscopy observation for thermally treated (at 400 and $600^{\circ} \mathrm{C}$ ) samples, showed homogeneous layers without cracking.
\end{abstract}

Key words: mesoporous, surfactant, sol-gel, membrane, inorganic

\section{INTRODUCTION}

In recent years, the use of $\mathrm{TiO}_{2}$, as membrane inorganic has aroused great interest in several industrial applications. This is because they offer many advantages over organic counterparts in separation process due to their thermal, mechanical and chemical characteristics.

One of the most widely used methods for the preparation of mesoporous Titania with different structures in the last decades has sol-gel processing ${ }^{[1-7]}$.

With this method a network of partially hydrolyzed and polycondensed monomers diluted in the solvent is formed. A mesoporous structure is obtained upon layer application (coating), drying and calcination.

The aim of this research is the use of sol-gel process to preparation of mesoporous Titania to contribute to synthesis of membrane. The effects of addition of surfactant $\left(\mathrm{CH}_{3}\left(\mathrm{CH}_{2}\right)_{15} \mathrm{~N}\left(\mathrm{CH}_{3}\right)_{3} \mathrm{Br}\right)$ on pore diameter and sol stability have been investigated.

Additionally, the thermal evolution, structural characteristics of calcined powders and films were studied.

\section{MATERIALS AND METHODS}

Synthesis: Titanium dioxide was prepared ${ }^{[2,4]}$, by the hydrolysis and condensation of titanium isopropoxide $\mathrm{Ti}\left(\mathrm{O}\left(\mathrm{C}_{3} \mathrm{H}_{7}\right)_{4}\right.$ (Aldrich) used as precursor under acidic conditions, with addition of surfactant, cetyltrimethylammoniumbromide

$\left(\mathrm{CH}_{3}\left(\mathrm{CH}_{2}\right)_{15} \mathrm{~N}\left(\mathrm{CH}_{3}\right)_{3} \mathrm{Br}=\mathrm{CTAB}\right.$, $)$ (Aldrich) to control pore diameter by varing the concentrations of $\mathrm{CTAB}$ in the solution. The values of molar ratio $\mathrm{R}=[\mathrm{CTAB}] /[\mathrm{Ti}-$ alkoxide] were: $0-0.5$ and 1). A specific amount of $\mathrm{Ti}\left(\mathrm{O}\left(\mathrm{C}_{3} \mathrm{H}_{7}\right)_{4}\right.$ was dissolved in equal volume of ethanol and mixed with deionized water.

Titanium isopropoxide is highly reactive in the presence of water. Left uncontrolled, titanium alkoxide would react and form an insoluble titanium oxide gel precipitate.

For a given titanium concentration, the hydrolysis condensation reactions were mainly governed by two parameters, namely the initial hydrolysis ratio $\left[\mathrm{H}_{2} \mathrm{O}\right] /[\mathrm{Ti}]$ and the inhibitor ratio $\left[\mathrm{H}^{+}\right] /[\mathrm{Ti}]$. Controlled hydrolysis of alkoxide precursors is the key to making thin films using the sol-gel process. The scheme of preparation is illustrated in Fig. 1.

Corresponding Author: T. Benkacem, Departement of Chemistry, Laboratory of Physico-Chemistry of Materials and Environment, Uuniversity of Sciences and Technology Houari Boumediene, Bp 32 El Alia Bab Ezzouar Algiers, Algerie 




Fig. 1: Steps preparation of $\mathrm{TiO}_{2}$ oxide powder in presence of $\mathrm{CTAB}$. $\mathrm{Ti}(\mathrm{OiPr})_{4}=$ Titanium isopropoxide $=\quad \mathrm{Ti}\left(\mathrm{OC}_{3} \mathrm{H}_{7}\right)_{4}$. Cetyltrimethylammoniumbromide= $=$ $\left.\mathrm{CH}_{3}\left(\mathrm{CH}_{2}\right)_{15} \mathrm{~N}\left(\mathrm{CH}_{3}\right)_{3} \mathrm{Br}\right)=\mathrm{CTAB}$

The synthesis mode was chosen as a maximum of connection formation: Ti-O-Ti. Thus, in a first step the idea is to use hydrolysis water by forming a maximum of connection of groupings Ti-OH.

Characterization: Powder XRD data were carried out with a Philips PW 1830 diffractometer with $\mathrm{CuK} \alpha$ radiation $(\lambda=1.5406 \AA)$. TGA curves were obtained in flowing nitrogen on TGA 2050 with a temperature increasing rate of $10^{\circ} \mathrm{C} / \mathrm{mn}$.

$\mathrm{N}_{2}$ adsorption-desorption isotherms were recorded on a Micromeritics ASAP 2010 automated sorption analyzer. The samples were outgassed at $150^{\circ} \mathrm{C}$ before the analysis. The FTIR spectra of samples were obtained using the $\mathrm{KBr}$ wafer technique. We have applied the Barret-Joyner-Halende (BJH) method to the determination of pore size.

Scanning electron microscopy is used to characterize membrane morphology, that is, the thickness and its homogeneity along the support.

\section{RESULTS AND DISCUSSION}

Infra-red spectra were recorded for every powder prepared with molar ratio [CTAB]/[Ti-alkoxide] equal to 0-0.5 and 1) treated at different temperatures (Fig. 2). Infra-red studies show that some $\mathrm{OH}$ remains in the titanium oxide. These $\mathrm{OH}$ groups are responsible of the membrane reactivity. The Ti-OH groups may be characterized by an absorption band situated at $500 \mathrm{~cm}^{-1}$. Above temperature $450^{\circ} \mathrm{C}$, we notice only

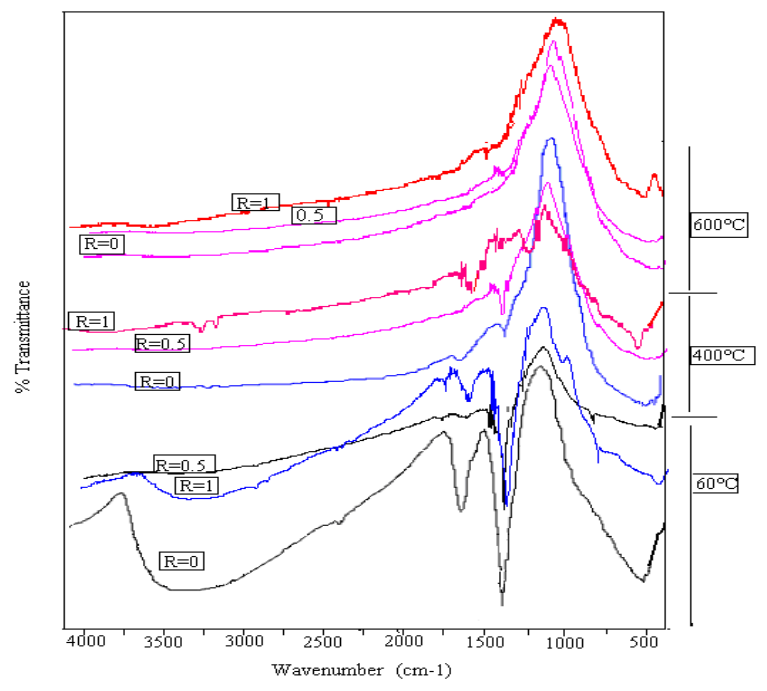

Fig. 2: Infra-red spectra of powders prepared with different surfactant ratio $[\mathrm{CTAB}] /[\mathrm{Ti}]$ and treated at different temperatures

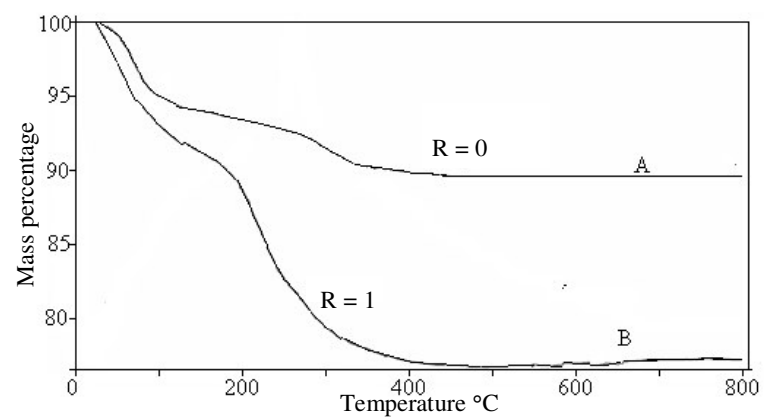

Fig. 3: TGA curves of powders recorded for assynthesis samples, (A): Without surfactant, (B): With ratio $[\mathrm{CTAB}] /[$ Ti-alkoxide $]=1$

the bands between 500 and $1200 \mathrm{~cm}^{-1}$. we notice that connection Ti-O-Ti are initially in the gel; this confirm the alkoxide polymerization.

Thermogravimetric analysis: The TGA of the assynthesized samples under $\mathrm{N} 2$ showed the loss of water below $120^{\circ} \mathrm{C}$ and surfactant loss started at $180^{\circ} \mathrm{C}$ and was completely removed at about $350^{\circ} \mathrm{C}$ (Fig. 3). The analysis of as-synthesized sample on heating to $450^{\circ} \mathrm{C}$, revealed $30.52 \%$ total weight loss for a sample without surfactant, ratio[CTAB $] /[$ Ti-alkoxide $]=0$ (Fig. 3a) and $52 \%$ total weight loss with ratio equal to 1 (Fig. $3 \mathrm{~b}$ ). The first effect is attributed to the release of adsorbed water, the second to desorption and decomposition of the surfactant and the third to dehydroxylation of the surface and removal of little residual surfactant. 


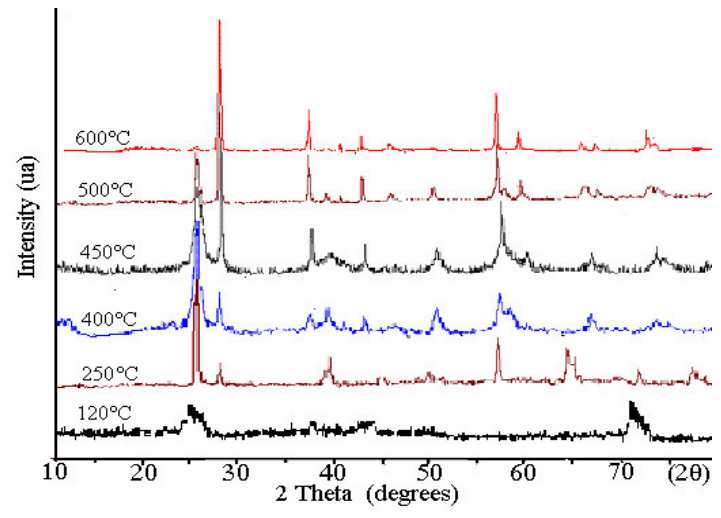

Fig. 4: Temperature programmed XRD spectra of powders at different temperatures

By X-ray diffraction: Temperature programmed XRD spectra shown in Fig. 4 compares the XRD patterns of powders with different ratio [CTAB]/[Ti-alkoxide] treated at different temperature.

It can be seen that the material without $\mathrm{CTAB}$ retains amorphous structure until $60^{\circ} \mathrm{C}$, while at $200^{\circ} \mathrm{C}$, a phase transformation into the crystalline anatase phase occurred.

Above this temperature $200^{\circ} \mathrm{C}$ we obtained a mixture of two forms anatase and rutile. While a patterns of powders containing $\mathrm{CTAB}$ present a broad peak, charasterising of Anatase up to $300^{\circ} \mathrm{C}$. Only the changes of phase content Anatase: Rutile were observed, when a both ratio of $\mathrm{CTAB}$ and heattreatment increase. Above the temperature $400^{\circ} \mathrm{C}$ the transformation of phase anatase to rutile according $\mathrm{CTAB} / \mathrm{Ti}$-alkoxide molar ratio and heat-treatment were similar.

Anatase and rutile are the two forms of titanium dioxide produced in laboratory at atmospheric pressure.

\section{TEXTURAL CHARACTERIZATION BY NITROGEN ADSORPTION-DESORPTION}

$\mathrm{N}_{2}$-sorption isotherms were recorded for 350,400 , 500 and $600^{\circ} \mathrm{C}$ calcined mesoporous structured samples and are shown in (Fig. 5). The shape of these curves is of type IV, typical of mesoporous materials. The physisorption isotherm of the sample with and without surfactant treated at $350^{\circ} \mathrm{C}$ is similar as sample treated at $600^{\circ} \mathrm{C}$.

Table 1 lists the specific surface area, the pore volume and the pore size data measured from $\mathrm{N}_{2}$ adsorption-desorption isotherms for titanium oxide samples as-synthesized and heat-treated at various temperature.

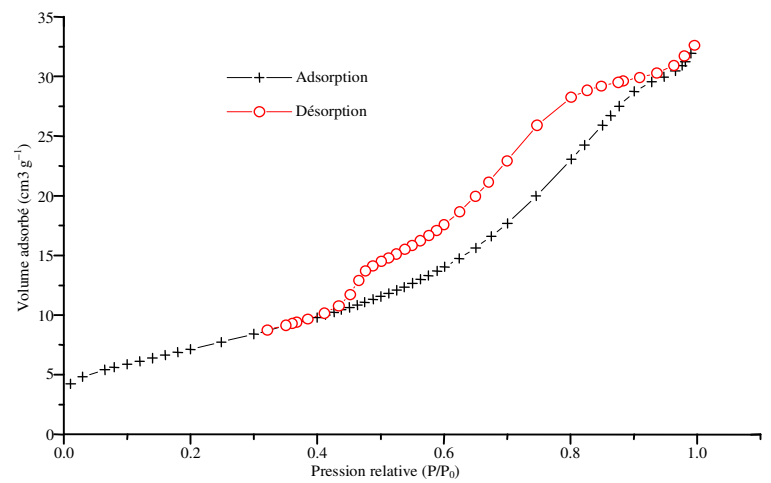

Fig. 5: Adsorption-desorption isotherm of sample using $\mathrm{N} 2$ at $77 \mathrm{~K}$

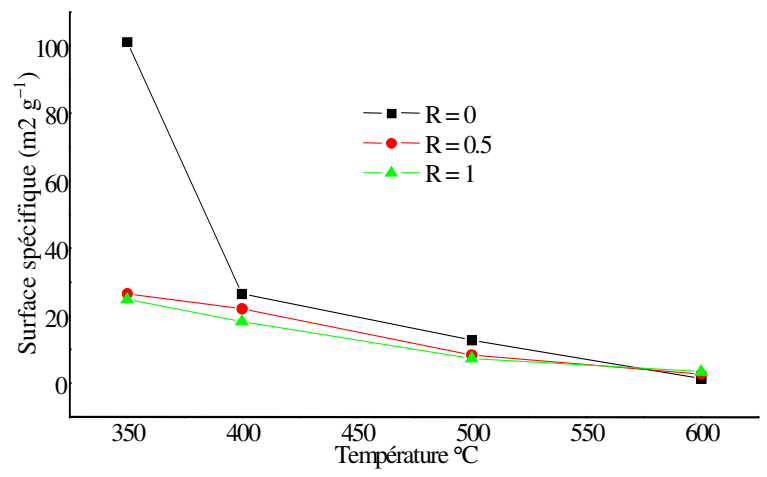

Fig. 6: Evolution of specific surface area as a function of the temperature and surfactant molar ratio

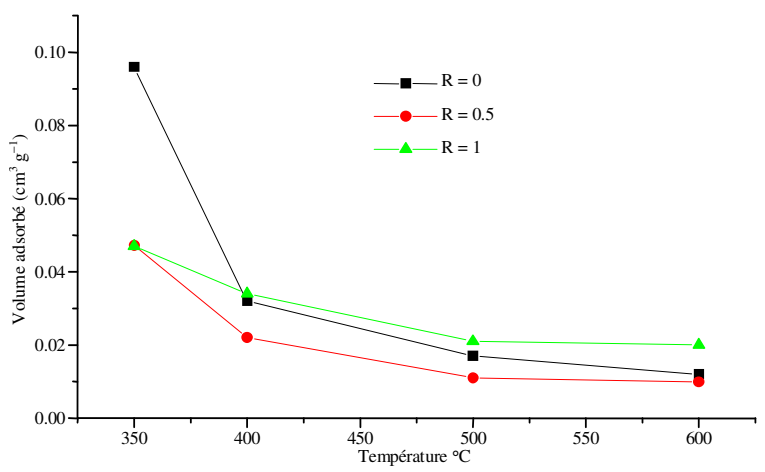

Fig. 7: Evolution of pore volume as a function of the temperature and surfactant molar ratio

With increasing of calcined temperature, the specific surface area and the pore volume began to decrease as shown in Fig. 6, 7. The mesostructured produced after calcination at $350^{\circ} \mathrm{C}$ has a BrunuerEmmett-Teller (BET) surface area of $101 \mathrm{~m}^{2} \mathrm{~g}^{-1}$. Between 350 and $600^{\circ} \mathrm{C}$, the specific surface area 
Table 1: Shows the preparation conditions and physical properties of powders treated at different temperatures

$[\mathrm{CTAB}] /[$ Ti-alkoxide $]$ molar ratio

\begin{tabular}{llll}
$\begin{array}{l}\text { Temperature } \\
\left({ }^{\circ} \mathrm{C}\right)\end{array}$ & $\begin{array}{l}\text { BET surface } \\
\text { area }\left(\mathrm{m}^{2} \mathrm{~g}^{-1}\right)\end{array}$ & $\begin{array}{l}\text { Pore diameter } \\
\left(\mathrm{A}^{\circ} \mathrm{C}\right)\end{array}$ & $\begin{array}{l}\text { Pore volume } \\
\left(\mathrm{cm}^{3} \mathrm{~g}^{-1}\right) \times 10^{3}\end{array}$ \\
\hline 400 & $0 / 0.5 / 1$ & $0 / 0.5 / 1$ & $0 / 0.5 / 1$ \\
450 & $101 / 26 / 24$ & $19 / 68 / 73$ & $96 / 47 / 47$ \\
500 & $26 / 22 / 18$ & $24 / 72 / 99$ & $32 / 22 / 34$ \\
600 & $12 / 08 / 07$ & $29 / 75 / 120$ & $17 / 11 / 21$ \\
\hline
\end{tabular}

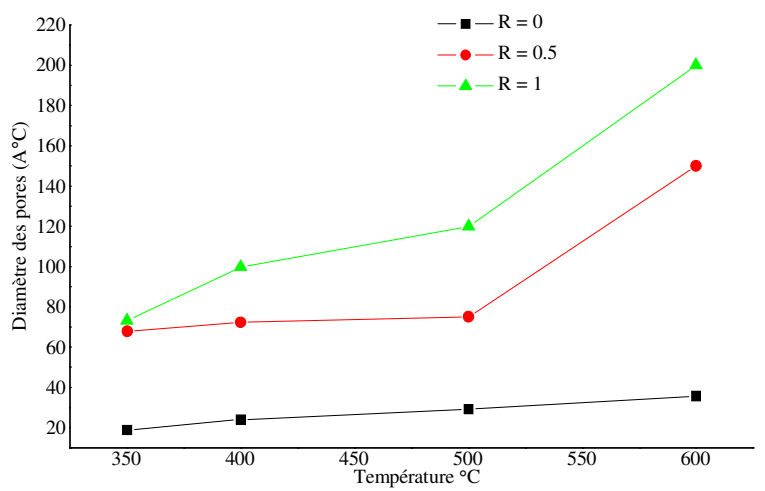

Fig. 8: Evolution of pore diameter as a function of the temperature and surfactant molar ratio

decreased from 101 to $2 \mathrm{~m}^{2} \mathrm{~g}^{-1}$. Which could be attributed to the crystallisation of the structured titanium oxide.

The effects of $[\mathrm{CTAB}] /[$ Ti-alkoxide] molar ratio and the heating on structured titanium oxide assynthesized have been studied. The changes in the molar ratio of $[\mathrm{CTAB}] /[$ Ti-alkoxide] showed that it play a key role in the formation of mesostructured titanium oxide.

With increasing of CTAB concentration, the specific surface area and pore volume decrease. While in the same time we notice (Fig. 6, 7, 8) that the pore diameter increased from $24 \mathrm{~A}$ to $99 \mathrm{~A}^{\circ} \mathrm{C}$ and from $36 \mathrm{~A}$ to $199 \mathrm{~A}^{\circ} \mathrm{C}$ by increasing of $[\mathrm{CTAB}] /[\mathrm{Ti}$-alkoxide] ratio from 0 to 1 on heating at respectively 400 and $600^{\circ} \mathrm{C}$ (Table 1).

These results indicated that as the calcination temperature increased, the number of pore decreased as a result of sintering while at the same time the pore size increased.

Deposits of thin porous layers: After the sol has been prepared, the titania layers were deposited by coating technique on mesoporous $\alpha$ alumina substrate presenting the pore diameter of $0.2 \mu \mathrm{m}$ on the usable face for deposit.

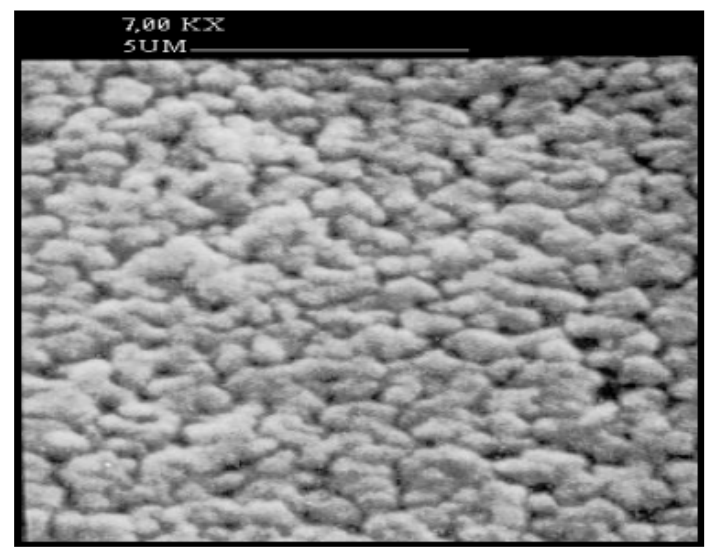

Fig. 9: Micrography of the layer obtained at $400^{\circ} \mathrm{C}$

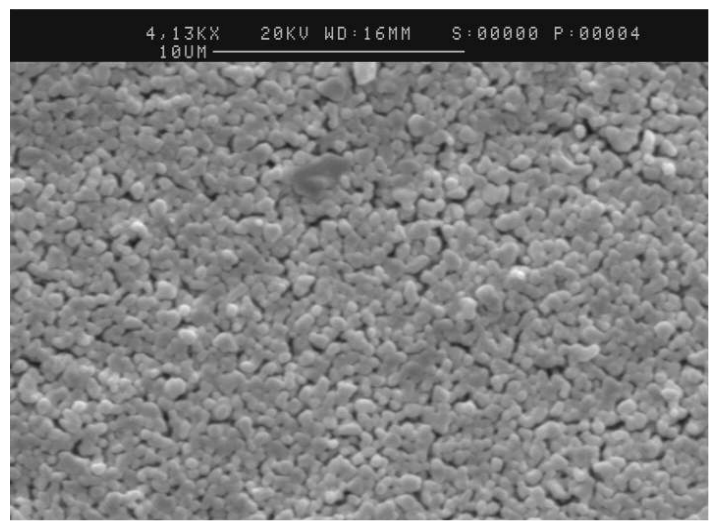

Fig. 10: Micrography of the layer obtained at $600^{\circ} \mathrm{C}$

The dried membranes were calcined at temperature 400 and $600^{\circ} \mathrm{C}$ respectively during $3 \mathrm{~h}$. (Fig. 9, 10, ).

Scanning electron micoscopy observation showed homogeneous layers without cracking (Fig. 9, 10, ).

It was found that the layer thickness could be varied in the range 1.85 to $1.25 \mu \mathrm{m}$ respectively for temperature 400 and $600^{\circ} \mathrm{C}$.

This is a very interesting fact because as indicated at results the mesoporous structure of titania oxide is in the range of ultrafiltration application.

\section{CONCLUSION}

In this study, we investigated the synthesis of mesoporous titania using titanium isopropoxide as precursor under acidic conditions. The effects of $[\mathrm{CTAB}] /[$ Ti-alkoxide] ratio and the heat-treatment on structured titanium oxide as-synthesized have been studied. The changes in the molar ratio of CTAB/Ti led 
to different value of pore diameter, specific surface area and pore volume.

It was found that polymeric sols could be obtained only when the hydrolysis conditions were strictly controlled.

We note increase of the pore diameters according to the concentration of surfactant while porous volume and specific surface decrease.

The control of sol-gel transition as well as thin layer deposit on a porous support $\alpha$ alumina has allowed us to contribute at the realization of ultrafiltration inorganic membranes.

\section{REFERENCES}

1. Sanchez, C., J. Livage, M. Henry and F. Babonneau, 1988. J. Non-cryst. Solids, 100: 65-76.
2. Anderson, M.A., M.J. Gieselmann and Q. Xu, 1988. J. Membr. Sci., 39 (3): 243-258.

3. Livage, J., M. Henry and C. Sanchez, 1988. Prog. Solid St. Chem., 18: 259.

4. Xu, Q. and M.A. Anderson, 1991. J. Mat. Res., 6 (5): 1073-1081.

5. Chen, K.C., T. Tsuchiya and J.D. Mackenzie, 1986. J. Noncryst. Solids, 81: 227.

6. Brinker, C.J. and G.W. Scherer, 1990. Sol-gel Science, Academic Press, New York.

7. Kims, J. and Y.S. Lin, 1998. J. Mat. Sci., 75: 39. 